\title{
La reelaboración de las fuentes en Polixena de José Marchena
}

\author{
LORETO Busquets \\ Università Cattolica del Sacro Cuore. Milán
}

Quod non vetat lex, hoc vetat fieri pudor.

Séneca, Troyanas

Trop de vertu pourrait vous rendre criminelle.

Racine, Andromaque, III, viii.

Resumen

La escasa y superficial atención que ha merecido la tragedia que es objeto del presente ensayo ha dejado prácticamente intacto cuanto dijo de ella Menéndez Pelayo en su conocido estudio crítico-biográfico que precede las obras de José Marchena por él recogidas y publicadas ${ }^{1}$ : no sólo en cuanto al juicio de valor, sino a la identificación de las fuentes discernibles en Polixena. Se presenta aquí una identificación concreta de dichas fuentes y un estudio de la reelaboración de las mismas que pongan en evidencia la urdimbre oculta del texto, no sólo para mostrar la deuda que Marchena tiene contraída con sus antecedentes o los cambios más o menos arbitrarios aportados a la fábula, sino también la originalidad de su invención allí donde ha introducido variaciones y cambios. Con ello pretendo dedicar atención a una obra menos insignificante e insulsa de lo que suele considerarse e intentar una interpretación orgánica de una obra que se distingue y aparta del cliché que conforma la tragedia neoclásica española, por su contenido y aun por su forma.

Palabras clave

José Marchena. Polixena. Tragedia.

1 Marcelino Menéndez Pelayo, Introducción a Obras literarias de don José Marchena, t. I, Sevilla, Imp. de E. Resco, 1892.

CES.XVIII, núm. 16 (2006), págs. 51-75. 
Como afirma Racine en el segundo prefacio de su Andromaque citando a un antiguo comentador de Sófocles: «Il ne faut point s'amuser à chicaner les poètes pour quelques changements qu'ils ont pu faire dans la fable; mais qu'il faut s'attacher à considerer l'excellent usage qu'ils ont fait de ces changements, et la manière ingénieuse dont ils ont su accommoder la fable à leur sujet ${ }^{2}$. Mostrando los cambios aportados a la fable y el uso que Marchena hace de ellos, es mi intención descubrir el verdadero sujet de la pieza, sobre el que la crítica hasta ahora ha dicho muy poco.

Como ya indicara Menéndez Pelayo en el prólogo citado, se descubren en Polixena «felices imitaciones» de Eurípides, Virgilio, Séneca y Racine así como de «otros clásicos antiguos y modernos» no especificados. Entre las obras modernas enumera seis Polixenas francesas y varias óperas. En cuanto a los «clásicos modernos», Rinaldo Froldi menciona las piezas francesas de Legouvé, de 1874, y de Aignau, de 1804, ya indicadas por Menéndez Pelayo, las cuales, a su juicio, no han tenido «influencia alguna en el texto de Marchena» ${ }^{3}$. Ya veremos, por el contrario, la importancia de la pieza de Legouvé en el mosaico de las fuentes que concurren en la elaboración del mito de Polixena en manos de nuestro dramaturgo, como bien había intuido Menéndez Pelayo: «Creemos que Marchena sólo conoció o tuvo presente la tragedia de Légouvé, pero su principal modelo fue la Andrómaca» ${ }^{4}$. La obra de Racine, que con razón constituye si no el «principal modelo», uno de sus principales modelos ${ }^{5}$, es apenas mencionada por Froldi.

En la antigüedad clásica, la figura de Polixena, exclusivamente vinculada a su sacrificio, suele tener un papel irrelevante como personaje escénico al punto que ninguna de las tragedias que ha llegado íntegra hasta nosotros lleva por título su nombre. Se sabe de la existencia de tres Polixenas griegas: una de Sófocles, una de Nicómaco de Alejandría, de las que quedan unos pocos fragmentos ${ }^{6}$, y otra de Eurípides, perdida. En Hécuba y las Troyanas de Eurípides, en la Eneida de Virgilio (III, vv. 320 y ss.), en la Metamórfosis de Ovidio (XIII, vv. 429-575) y en las Troyanas de Séneca ${ }^{7}$ se dedica un espacio más o menos relevante a la inmolación de Polixena y al dolor que inspira a quienes asisten a ella, especialmente a su madre Hécuba. En ellas el causante de su muerte, y a veces el ejecutor material

2 Jean Racine, Andromaque, en Racine, Théâtre complet, París, Garnier, 1960, pág. 118.

3 Rinaldo Froldi, La tragedia «Polixena» de José Marchena, en Teatro español del siglo XVIII, 2 vols., ed. Josep Maria Sala Valldaura, Lleida, Universitat de Lleida, 1996, I, pág. 405.

4 Loc. cit., nota 58.

5 Díaz-Plaja liquida Polixena con un simple «pobre imitación de Racine» (Fernando DíAz-Plaja, Prólogo, en Abate Marchena, Obra en prosa, cit., pág. 12).

6 En Tragicorum Graecorum Fragmenta, IV, Göttingen, Vandenhoeck \& Ruprechet, 1999, págs. 403-407.

7 Todas las referencias y citas de los textos grecolatinos se refieren a las ediciones parisinas de «Les Belles Lettres»; cito los textos latinos en la lengua original y los griegos en traducción. 
de la misma, es Neoptolemo, esto es, Pirro. En las Troyanas de Eurípides, Hécuba menciona a su hija Polixena creyéndola todavía viva y es Andrómaca quien narra en un solo verso el consumado sacrificio: «Ta fille Polyxène a perit égorgée sur le tombeau d'Achille» (vv. 622-623); en Hécuba del mismo, Polixena interviene repetidas veces en relación a su inminente destino y en el momento del sacrificio, profusa y bellamente narrado (vv. 553 y ss.), mientras que en las Troyanas de Séneca es personaje mudo, no sólo ante la inminencia de su muerte sino a lo largo del cuarto acto (vv. 861-1008), cuando se decide de su suerte. Virgilio, fiel al texto euripideo, hace hablar a Polixena directa y extensamente (respecto a la duración del episodio dedicado a ella): «Utere iamdudum generoso sanguine», etc. (Metamórfosis, vv. 457-473). En ambas Troyanas, pues, las verdaderas protagonistas son Hécuba y su hija Andrómaca, ésta, a su vez, protagonista femenina de la Andromaque de Racine junto a la figura antagonista de Hermione. En esta obra, ambas mujeres, en un juego de simetrías y quiasmos de gusto clásico, o más bien barroco, se hallan emparejadas con las figuras masculinas de Pirro y Orestes, todos ellos, a su vez, emparejados con sus respectivos confidentes, los cuales sólo muy parcialmente cumplen la función del coro presente en las tragedias clásicas citadas. En esta obra se destaca por vez primera el amor no correspondido de Pirro por Andrómaca, paralelo al de Orestes por Hermione, con la consabida cadena raciniana de Oreste que ama a Hermione, que ama a Pyrrhus, que ama a Andromaque, que ama a Hector, etc.

Sólo Gabriel-Marie Legouvé (París, 1764-1812), profesor de poesía latina en el Collège de France, director del Mercure de France desde 1807 a 1810, oscuro dramaturgo del periodo postrevolucionario que gozó de efímera e intensa fama durante el último decenio del siglo XVIII, hoy casi olvidado o apenas mencionado como autor insulso y rutinario, otorga una posición central al personaje de Polixena al punto de dar el título a su tragedia. En ella la más joven de la numerosa prole de Hécuba es amada por Pirro en términos muy parecidos a los de Pirro por Andrómaca en la pieza raciniana. Tales amores, en curioso contraste con el mito, que hace de Neoptolemo el guerrero por antonomasia, brutal, cruel y sanguinario, ajeno a veleidades o debilidades amorosas, y en cualquier caso en contraste con la tradición, que lo ve ligado a la figura de Andrómaca por razón del sorteo a que son sometidas las troyanas tras la derrota, encuentran amplia fortuna, especialmente durante todo el siglo XVIII, en ámbito musical operístico. En España contamos con el melólogo de Fermín del Rey musicado por Blas de Laserna $^{8}$, pero en Francia son varias las óperas que tratan de ellos, entre las

8 Véase al respecto J. SuBIRÁ, El compositor Iriarte y el cultivo español del melólogo, Barcelona, CSIC, 1950, II, págs. 345-350. 
que destaco: Achille et Polyxène de Jean-Baptiste Lully (Opéra de París, 1687), Polyxène et Pyrrhus de Pascal Collasse (Opéra de París, 1706) y sobre todo el «dramma per musica» Pirro de Giovanni Paisiello con libreto de Giovanni De Gamerra, estrenado en Nápoles el 12 de enero de $1787^{9}$.

Siguiendo probablemente a Racine, Legouvé coloca al lado de las dos protagonistas femeninas, Polixena y su madre Hécuba, las figuras masculinas de Pirro y Ulises flanqueados por sus respectivos «confidentes», dejando pues el diálogo entre madre e hija desprovisto de intermediarios. A parte de los figurantes (sacerdotes, griegos y soldados), Legouvé reduce a siete los ocho personajes de Racine, descomponiendo la rigurosa simetría de las parejas racinianas con la figura siniestra del sacerdote y adivino Calcas, que adquiere en esta obra una significativa centralidad.

Siete son también los personajes en la Polixena de Marchena ${ }^{10}$. La simplificación operada por ambos autores con respecto al modelo raciniano responde sin duda al gusto neoclásico por la brevitas, la perspicuidad y la claridad geométrica, reforzada mediante paralelismos y simetrías: dos co-protagonistas, Pirro y Polixena, flanqueados, como sombras de sí mismos, por sus respectivos confidentes, Hécuba, que asume rasgos de la Andrómaca de Racine y funciona de intermediaria entre Pirro y Polixena, y la pareja Ulises-Calcas, el primero presente en Hécuba de Eurípides y ambos en las tragedias de Séneca y Legouvé, que en esto se distingue de la Andromaque de Racine, donde el portador de la voluntad de los griegos y quien trata directamente con Pirro es Orestes y no la interpuesta persona de Ulises.

Que Marchena tiene delante la pieza de Legouvé lo demuestran, por empezar, las acotaciones relativas al lugar «único» de la acción. La sola acotación de Legouvé ( «Le théâtre représente, d’un côté, les ruines de Troie; dans le fond, le tombeau d'Achille, et dans le lointain, l'Hellespont couvert de vaisseaux ${ }^{11}$ ) en Marchena se desdobla en dos tiempos: la primera acotación se refiere a los dos primeros actos («La escena en el primero y segundo acto representa la tienda real de Pirro, el campo de los Mirmidones, el Helesponto, y a lo lejos las ruinas de Troya») y la segunda, una parte de la escenografía prevista en la obra francesa, al tercero y último acto: «Es de noche. La escena representa el túmulo de Aquiles ornado de cipreses, y el fuego sagrado que arde a sus manes».

$9 \quad$ En esta ópera se narra del matrimonio de Pirro y Polixena contrastado por los griegos, de la conspiración de Ulises para eliminar a Polixena, del oráculo de Calcas que manda vengar la muerte de Aquiles, y del mismo Calcas que conduce a Polixena al ara sacrifical; a última hora el oráculo manda liberar a Polixena y Pirro consiente en que ésta case con el príncipe troyano Darete.

10 Me refiero siempre a la edición a cargo de Menéndez Pelayo citada en la nota 2.

11 Cito siempre de la siguiente edición: Polixène, en Oeuvres inédites de G. Legouvé, Poëmes et Tragédies, París, Louis Janet, Libraire, 1827. 
Como en Legouvé, la Polixena de Marchena suma a los rasgos que le son propios los de su hermana Andrómaca, del mismo modo que, con respecto a Racine, Pirro, en cuanto enamorado, asume con sus propias connotaciones las de Orestes, y Ulises, en cuanto portador de la voluntad de los griegos, las de Orestes y su padre Agamenón. La superposición de las dos figuras femeninas le permite a Marchena concentrar en Polixena los rasgos de la «mujer amante», separándola así de la «mujer madre», que reserva a Hécuba, y que en Andromaque aparecen fundidas en la figura de Andrómaca. Es más. El protagonismo otorgado a Polixena le consiente hacer confluir en su sacrificio no sólo la versión novelesca tardía de sus frustradas bodas con Aquiles, durante las cuales éste encontró la muerte ${ }^{12}$, sino también la leyenda del amor correspondido de Aquiles por Polixena y el suicidio de ésta tras el asesinato del héroe ${ }^{13}$. Con ello establece un nexo implícito con el mito de Ifigenia, engañosamente conducida a Aulis con el pretexto de ser unida en matrimonio con Aquiles (Eurípides, Ifggenia en Aulis).

Es probable que la incorporación de los amores y bodas de Aquiles se la hayan sugerido a Marchena no sólo Legouvé, quien los menciona en el primer diálogo entre Pirro y Phénix ${ }^{14}$, sino también y sobre todo las Troyanas de Séneca, donde Helena, con un pretexto falaz, hace creer a Polixena que en vez de dirigirse al propio holocausto, como Ifigenia, va a contraer matrimonio con Pirro (vv. 871 y ss). En cualquier caso, la insistencia en la mitografía que une el desposorio a la muerte revela la importancia simbólica que Marchena, siguiendo a Séneca, otorga al sacrificio thalami more (Troyanas, v. 1132), y la función de lo que Barthes denomina «une sorte d'erotisme funebre» en la «fidelidad» amorosa, ligada a la memoria ${ }^{15}$.

Por su parte, el enfrentamiento Polixena / Pirro, en su esquemática sencillez, propone un interesante desdoblamiento especular. El amor de Aquiles por Polixena es revivido ahora por su hijo Pirro en condiciones prácticamente idénticas («Aquiles / ardió en los mismos fuegos inflamado», III, iv): aquél había pedido a Príamo que le concediera la mano de su hija Polixena prometiéndole pasar al bando de los troyanos, lo mismo que Pirro trata de hacer ahora con el apoyo de Hécuba, replanteándose la misma cuestión de «fidelidad» e incompatibilidad política que en su día costara la vida a Aquiles y que ahora costará la

\footnotetext{
12 Algunas versiones atribuyen la muerte de Aquiles enamorado de Polixena a Alejandro (= Paris) y Deífobo (Higinio, Fábulas, fábula CX); otras, la mayoría, a Paris, o a Paris y Apolo, aunque no necesariamente durante la celebración de la boda.

13 Versión registrada en Flavii PhiLostrati, Heroicus, ed. L. de Lannoy, Leipzig, B.G. Teubner, 1977, y en la Vida de Apolonio (IV 16, 4) del mismo autor.

14 «Qui, conduite aux autels pour s'unir à mon père» (I, ii).

15 Roland Barthes, Sur Racine, París, Éditions du Seuil, 1963, pág. 75.
} 
vida a Polixena. Una identidad de fondo se delínea entre la antigua concesión de Príamo (no explicitada en la obra que nos ocupa) y la presente negociación de Hécuba con vistas a alcanzar una pacificación entre los dos países en pugna, evitando con ello un sacrificio «bárbaro», cruel e inhumano ${ }^{16}$, además de innecesario. Resulta ya evidente que la trama amorosa encubre una cuestión política, social y humana que interesa particularmente a Marchena. Pero antes de llegar a ello, veamos de qué modo reelabora las fuentes discernibles en su obra.

\section{Acto primero}

La tragedia da comienzo con Polixena en diálogo con su nodriza y confidente, Terpandra, un nombre de invención de Marchena que no he encontrado documentado en ninguna parte. En él se esboza lo que evidentemente para nuestro dramaturgo constituye el núcleo de su obra: la posibilidad que le ofrece Pirro de liberarse de la esclavitud presente y de levantar a Troya de su ruina accediendo a su matrimonio. La obra, pues, inicia con el peso de una responsabilidad social y política que grava sobre la protagonista, en la que se insiste reiteradamente: «las esperanzas / de la infelice Troya en vos se fundan; [...] Del pequeño Astianacte las cadenas / vais a romper, de vuestra madre anciana / vais en fin a enjugar el llanto amargo...» (I, i); y, más adelante, en las palabras que Marchena pone en boca de Pirro: «Yo te ofrezco levantar de Troya / las torres por mí mismo derrocadas, / de tu madre enjugar el triste llanto, / coronar a Astianacte, y de su infancia / proteger la flaqueza con mi brazo» (I, ii).

Las huellas de Andromaque de Racine son ya visibles en este incipit. No es casual que los versos castellanos mencionen a Astianacte, el hijo de Andrómaca en peligro, que en Racine es la víctima reclamada por los Griegos y objeto de la contienda. Pero la imitación prosigue en las palabras de Céphire, la confidente («De l'espoir des Troyens seule dépositaire, / Songe à combien de rois tu deviens nécessaire», IV, i), y en las que Pyrrhus dirige a la obstinada Andrómaca («je puis tout entreprendre: / Votre Ilion encor peut sortir de sa cendre», I, iv), casi idénticas a las de nuestro Pirro: «vos podéis de la alta Troya / levantar las murallas arruinadas» (I, ii).

También la pieza de Legouvé se abre con la figura co-protagonista de Pirro en diálogo con su confidente. En él le habla de la pasión amorosa que le devora, de las contradicciones del ánimo humano, del poder desestabilizador del amor, de

16 Estos términos recurren con frecuencia en Polixena y en los escritos políticos de Marchena, pero también en los dos modelos franceses aquí considerados. 
una crisis, en suma, que amenaza su integridad psíquica: «Suis-je encore Pyrrhus? Suis-je le fils d'Achille?» (I, i). Con mayor o menor fortuna, está claro que Legouvé, a diferencia de nuestro dramaturgo, sigue la línea de la introspección y del análisis psicológico del que Racine es maestro unánimemente admirado e imitado. Tanto es así que el planteamiento «político» que Marchena presenta al auditorio en abertura, Legouvé lo desplaza al inicio del segundo acto, cuya primera larga escena es ocupada por el diálogo entre Polixena y Hécuba, en quien confluyen los roles de confidente y madre.

Las palabras iniciales del drama, en boca de Polixena en el caso de Marchena y de Pirro en el de Legouvé, sirven para poner al público en antecedentes sobre el incendio y destrucción de Troya, anteriores a la acción que es objeto de sus obras. En el relato no falta la alusión al asesinato de Príamo por obra del propio Pirro, y a la muerte de Héctor, que en Racine (III, vi) ocupa obviamente un puesto relevante. En este recuento, del que sucesivamente se añaden nuevos episodios a modo de fragmentos que van acudiendo a la memoria del narrador (especialmente en II, ii), Marchena y sus fuentes siguen el patético relato virgiliano del libro segundo de la Eneida: el cruel asesinato de Príamo procede de los vv. 533-553, mientras que el «Mi mano, que rompió las fuertes puertas / de durísimo bronce, que guardaban / de Príamo el palacio» (II, ii) remiten a los vv. 479-481 ${ }^{17}$. Pero, en nuestro caso, la mención de los primerísimos versos a la inestabilidad de la Fortuna («Hoy esclava / mañana seréis reina», I, i) envía al poderoso exordio de las Troyanas de Séneca ${ }^{18}$ y a la sucinta descripción en boca de Hécuba de la ruina de Troya, con el recuerdo de Pérgamo, la caída de los muros, el pavoroso incendio y el feroz asesinato de Príamo («Vidi execrandum regiae caedis nefas»..., vv. 44 y ss.), que nuestra Polixena describe en términos afines: «su acero bañó la sangre helada / de mi padre» (I, i). El nombre de Príamo, que en el ánimo de la protagonista genera el recuerdo del «generoso» Aquiles ${ }^{19}$ en contraposición a la despiadada crueldad de Pirro, conduce en cambio y de nuevo a Racine, no sólo por la identidad de los versos («Jadis Priam soumis fu respecté d’Achille», III, vi), que se remontan al episodio en que Aquiles se mostró piadoso

\footnotetext{
17 Dicen así: «Ipse inter primos correpta dura bipenni / limina perrumpit postisque a cardine vellit / aeratos»; como observara ya Menéndez Pelayo, la mención del asesinato de Polites (II, ii) proviene de los vv. 526-532 del mismo libro.

18 También la Hécuba de Eurípides a Ulises: «Les puissants ne doivent pas abuser de leur puissance, ni croire, étant heureux, qu'ils le seront toujours. Moi aussi, je l'étais jadis; aujourd'hui je ne le suis plus; toute ma prospérité, un seul jour me l'a ravie» (Hécuba, vv. 282-285). También nuestro Pirro: «Hécuba, los humanos son juguete / de la fatalidad; la suerte varia / eleva y precipita ciegamente / al labrador humilde, y al monarca» (I, v).

19 «El hijo generoso de la diosa» (I, i); aquí y en adelante el epíteto épico «generoso» acompaña sistemáticamente el nombre de Aquiles, a quien Polixena sigue amando desde el día en que, llegada al altar para contraer matrimonio, cayó en manos de su hermano Paris.
} 
con su padre al entregarle su hijo muerto ${ }^{20}$, sino por la sutileza psicológica de hacer aflorar a la conciencia de Polixena de forma casi involuntaria el obsesivo recuerdo de su amado Aquiles, equivalente a las menciones involuntarias de la amada por parte del Pirro raciniano, y de Héctor por parte de Andrómaca, que denuncian la obsesión amorosa que muy a pesar suyo domina el ánimo de los protagonistas: «Cent fois le nom d'Hector est sorti de sa bouche»; «Commencez donc, seigneur, à ne m'en parler plus»; «Quoi! toujours Andromaque occupe votre esprit?» (II, v).

Se advierten asimismo los modelos franceses en el sofocado sentimiento de culpabilidad que atormenta la conciencia de los protagonistas ${ }^{21}$. Tanto el Pirro de Legouvé como el de Racine sienten remordimientos por las crueldades ejercidas en su pasado de victoria y gloria: Racine: «De combien de remords m'ont-ils rendu la proie! / Je souffre tous les maux que j'ai faits devant Troie» (I, iv) y Legouvé: «Je sens même en secret des remords de ma gloire» (I, i); «Et les remords du sang où mon bras s'est trempé» (I, ii). También nuestra Polixena se siente culpable por haber amado al que fue destructor de los suyos y de su patria; se lo recuerda la inflexible Terpandra (a lo que ella: «¿Por qué me acuerdas ese horrible día?», I, i); ella, a su vez, echa en cara a Pirro sus pasadas atrocidades, a lo que éste: «¡Bárbara Polixena! ¿Así no basta / a tu crueza ver llorar a Pirro / sus hazañas, sus triunfos, y su fama, / sin que de una victoria aborrecida / le acuerdes siempre la memoria amarga?» (I, ii), parecidamente al Pyrrhus raciniano dirigiéndose a la irremovible Andromaque: «Haï de tous les Grecs, pressé de tous côtés, / Me faudra-t-il combatre encor vos cruautés?» (I, iv). Como se echa de ver en estos contrastados diálogos, los «confidentes» encarnan el Super-Yo, esto es, la Ley del Padre — la legalidad del Estado_ que incumbe sobre la conciencia; lo dice explícita y perentoriamente el Ulises de Legouvé: «Vous servez votre père, et les dieux, et l'État»; «Le ciel et votre père / Veulent ce sacrifice affreux, mais nécessaire»; «C'est un sang ennemi que vous devez haïr» (I, iii).

Sin abandonar la escena segunda, Marchena se adentra ahora en las bodas de Aquiles y Polixena, en las que se demora también Legouvé (I, ii), y en un presunto sueño de Casandra donde vienen a converger el conocido sueño de Hécuba, en el que, embarazada de Paris, había previsto que éste sería el tizón ardiente que incendiaría Troya ${ }^{22}$, y la predicción de Héctor según la cual Aquiles

20 Ilíada, XXIV, vv. 468-512, y VIRgILIo, Eneida, II, vv. 540-543: «At non ille»...

21 En opinión de Guazzelli la «angoscia del tradimento sembra essere il tema dominante dell'opera» (Francesco Guazzeldi, «Un neoclassico spagnolo: José Marchena», en Miscellanea di studi ispanici, núm. 16, Pisa, Università di Pisa, 1968, pág. 280).

22 Apollodoro, Biblioteca (III, 12, 5 y ss.), en I miti greci, Milán, Fondazione Lorenzo Valla-Arnoldo Mondadori Editore, 1996; lo recoge Legouvé en II, i. 
acabaría muriendo por manos de Paris y Apolo. La mención del «templo» en el v. 37 parece indicar que Marchena está pensando justamente en el templo de Apolo Timbreo, no lejos de las puertas de Troya, donde Paris, escondido detrás de la estatua de un dios, mata a Aquiles desarmado (Ilíada, XXII, vv. 359-360).

Protagonista de las escenas siguientes es Pirro, quien habla primero con Polixena ante la presencia de sendos confidentes (escena II) y luego con Hécuba (escena $\mathrm{V}$ y última), intercalando entre ambos parlamentos, que de hecho constituyen una larga negociación, el análisis introspectivo del propio Pirro, primero con su confidente Elpenor, cuyo nombre se remonta a la Odisea (X, vv. 551-560) sin conexión alguna con nuestro personaje, y luego consigo mismo en el solo que constituye la escena IV. El texto sigue todavía la Andromaque raciniana, cuando se produce el primer encuentro entre Pirro y Andrómaca a la presencia de la confidente de esta última. Cabe decir que también la Polixena de Legouvé sigue los mismos pasos (II, ii), por lo que es difícil determinar la fuente directa o intermediaria del texto que nos ocupa. Sea come fuere, la primera intervención de Pirro resume cuanto el Pyrrhus de Racine comunica a Andrómaca en la cuarta escena del primer acto, con las variantes que exigen la figura e historia personal de Polixena, reducida a sus bodas con Aquiles. Si en Racine los Griegos reclaman la muerte de Astianacte, en Marchena, fiel a otras fuentes, exigen el sacrificio de Polixena para vengar «la muerte alevosa» de Aquiles. Por lo demás, iguales son: el relato de cuanto solicitan los Griegos, la promesa de defender a Polixena aun oponiéndose a su propio pueblo y de subirla al trono (Astianacte en Racine, I, iv), el escaso temor que le inspiran las amenazas de sus conciudadanos, la manifestación de su amor, la condición de ser correspondido, implícita en Racine y explicitada en Marchena («si aceptáis mi homenaje») y la inversión de roles, con el monarca a los pies de su esclava en acto de pedir «piedad» a quien necesita de su piedad. Distinto es el tono del diálogo a que obliga la sustancial diferencia de ambas figuras femeninas: en Racine, una Andrómaca madura, fría, raciocinante, pronta al sarcasmo y casi al insulto (rasgos que, salvando las distancias, Legouvé trasplanta a su Polixena, II, ii); en Marchena, una joven Polixena con rasgos de la dulce y pura Andrómaca de la epopeya homérica (Ilíada, VI), enamorada de Aquiles como ésta de Héctor, resuelta y aun obstinada en su amor propio y en el alto sentido de la dignidad de su rango («en mis desdichas / no olvido que de Júpiter la clara / sangre corre en mis venas»), pero inflexible e impermeable a concesiones, compromisos y ruegos. Así y todo, el diálogo de Andromaque (I, iv) y el de nuestra Polixena (I, ii) discurren por los mismos cauces y desembocan en una negativa que se diría definitiva. Versos hay casi iguales: la mención de «el hijo del grande Héctor en la cuna / ignora todavía sus desgracias» remite, por ejemplo, al sarcástico «Digne objet de leur crainte! / Un enfant malhereux, 
qui ne sait point encor / Que Pyrrhus est son maître, et qu'il est fils d'Hector!», con que Andrómaca arremete contra su enamorado interlocutor.

El parecido persiste en la utilización del conflicto amoroso para delinear las cuestiones de razón y ética políticas que, como veremos, constituyen el verdadero «asunto» de ambas obras. Frente a la intransigencia de las dos mujeres, que apelan al resentimiento y a la venganza en nombre del amor propio y de los deberes patrios, pretextuosos en nuestra Polixena y por tanto no del todo sinceros, los dos Pirros muestran un sincero deseo de reparación ${ }^{23}$ : «Je souffre tous les maux que j'ai faits devant Troie», dice Pyrrhus (I, iv), y el nuestro: «Cuanto mayores son vuestras desdichas, / más gloria será mía repararlas» (I, ii). Ambos aspiran a poner fin a una hostilidad secular interrumpiendo la espiral de odio y de violencia que atenaza a sus pueblos: «Peut-on haïr sans cesse? et punit-on toujours?»; «Mais enfin, tour à tour, c'est assez nous punir» (I, iv).

A diferencia de Racine, donde el pueblo es simplemente «les Grecs», en Marchena, siguiendo acaso la sugestión de Séneca («magna pars vulgi levis / odit scelus spectatque», Troyanas, vv. 1128-1129) y por supuesto la tradición maquiavélica y barroca, es «vulgo» irracional e inconstante, maleable instrumento en manos de las astucias del Poder ${ }^{24}$ : «El que los demagogos llaman pueblo, y los prudentes vulgo ó plebe, siempre es guiado por un instinto de destrucción que le conduce derechamente á su ruina», escribe Marchena en $1812^{25}$. Desprecio que no le impide reflexionar sobre él siguiendo el esquema piedad / impiedad, humanidad / inhumanidad, civilización / barbarie ${ }^{26}$, de cuño clásico, senecano e ilustrado: «Mas nunca los excesos del populacho me harán olvidar los imprescriptibles derechos del pueblo» ${ }^{27}$. El íntimo contraste que opone al «piadoso»y «magnánimo» Aquiles el «inhumano» Pirro, mencionado por Polixena en el exordio, permite a este último amoldar ahora su conducta al modelo paterno: «Señora, vuestra suerte desdichada / respeta Pirro, ni inte-

${ }^{23}$ Sobre la sinceridad de las intenciones de Pirro no se engaña la experimentada Andrómaca («Je sais quel est Pyrrhus. Violent, mais sincère /, Céphise, il fera plus qu'il n'as promis de faire», IV, i) ni tampoco nuestra Hécuba: «Señor, a juramentos tan solemnes / una madre se fía» (I, v).

24 «Vulgo sedicioso», «vulgar furor», «impulso de una impía / muchedumbre sin freno» (II, 1); «los mismos que ora piden vuestra muerte / adorarán en vos su soberana»; «la insana cólera de la plebe, cual al viento / el humo se disipa, el tiempo calma» (I, iii); palabras que encontramos en el escrito dirigido al gobierno de Cádiz: «el vulgo tan presto exalta sus ídolos como los derriba» («Al Gobierno de Cádiz», en Marchena, Obra en prosa, cit., pág. 196).

25 Ibidem.

26 Séneca plantea la cuestión por medio de Agamenón: «noscere hoc primum decet, / quid facere victor debeat, victus pati. / violenta nemo imperia continuit diu» (vv. 256-258); «Morte misericors saepe pro vita dabit» (v. 329); «Quod non vetat lex, hoc vetat fieri pudor» (v. 334); «sed meus captis quoque / scit parcere ensis », dice siempre Agamenón (vv. 350-351).

27 Carta dirigida a Juan O'Donojú, en Obra en prosa, cit., pág. 222. 
rrumpe necio / el legítimo llanto que derraman / vuestros ojos» (I, ii ${ }^{28}$. La ética política sostenida por ese nuevo Pirro (en Séneca por Agamenón, encarnación de la «prudencia» y de la «piedad»), pone a los griegos, orgullosos de su «civilización» pese a su inhumana ideología del odio y de la venganza, en el banquillo de los acusados.

Las escenas III y IV de este primer acto, dedicado al diálogo confidencial de Pirro y Elpenor, siguen recurriendo al texto raciniano; lo confirma el « ¿Viste, Elpenor, cuál con desdén altivo / de mi pasión se burla?», paralelo al «Tu l'as vu comme elle m'a traité» (II, v) con que el monarca lamenta la reacción de Andrómaca ante su generosa propuesta. Elpenor, como el Phoenix de Racine (y el Phénix de Legouvé), es la voz de una ideología viril que mira con desprecio las debilidades del amor y pone en primer plano el respeto a la tradición y la sumisión a la ley. Voz de la conciencia, al punto que, en Marchena, están siempre al lado de los protagonistas como si fueran su propia sombra, los confidentes indican la vía de la razón según el paradigma del estoico «vencerse a sí mismo», que en este momento significa someterse a la razón política del Estado: «los inmensos, / los sagrados deberes del monarca / calmarán los tormentos del amante», exclama nuestro Elpenor siguiendo el ejemplo raciniano: «Je pensais que la guerre et la gloire / De soins plus importants rempliraient ma mémoire», afirma Orestes (I, i), y Pirro: «Dis plutôt qu'aujourd'hui commence ma victoire. / D'aujourd'hui seulement je jouis de ma gloire; / Et mon coeur, aussi fier que tu l'as vu soumis, / Croit avoir en l'amour vaincu mille ennemis». Aparente «conversión» que motiva el aplauso de los confidentes y amigos: «¡Cuánto, señor, a vuestro amigo es grata / resolución tan noble!»; «Hoy, de vos mismo vencedor, la Fama / vuestros loores cantará» (I, iii); y en Racine: «C'est n'est plus le jouet d'une flamme servile, / C'est Pyrrhus, c'est le fils et le rival d'Achille» (II, v).

Marchena no penetra en los entresijos del ánimo humano con la sagacidad de Racine, que en este diálogo alcanza uno de sus momentos más altos. Pero recoge del modelo la sutileza de mostrar los sentimientos de amor y de piedad que afloran en el ánimo de Pirro en el mismo instante en que parece haberse «vencido a sí mismo»: los versos, «¿Quién podrá contener su enojo ciego, / si la abandono yo?» (II, iii) muestran la misma preocupación amorosa de «Elle en mourra, Phoenix, et j'en serai la cause: / C'est lui mettre moi-même un poignard dans le sein», que Pyrrhus justifica a sí mismo como «un reste de tendresse» (II, v).

Llegado a este punto, Marchena introduce el tema de los celos, inexistente en Legouvé y en los modelos de la antigüedad clásica, haciendo confluir en la

28 La transformación es igualmente patente en Racine: «Que, malgré la pitié dont je me sens saisir, / Dans le sang d'un enfant je me baigne à loisir!» (I, ii). 
figura de Pirro los celos de Orestes y de Hermione de la tragedia raciniana. El solo que sigue a la explosión de ira que Elpenor trata de enfrentar mostrando lo infundado e irracional de la sospecha, sirve para mostrar al auditorio la sinceridad del propósito y de las promesas de Pirro, así como la sincera convicción de que Polixena ha sido la causante de la muerte de Aquiles, con lo que reaparece el sentimiento de culpabilidad hacia el padre y hacia «el interés sagrado» de la patria (I, iv) con que Pirro paga la «libertad» de rechazar la Ley de los padres.

El diálogo que éste mantiene con Andrómaca en la tragedia de Racine pasa aquí a Hécuba, en quien, como he anticipado, confluye el rol de su hija Andrómaca. En ella recae ahora la responsabilidad de salvar a su hija y también a Astianacte, de liberar de la esclavitud a las troyanas y de reconstruir a Troya. La «madre» se asume la responsabilidad que la joven e inexperta Polixena depone con su renuncia, y decide tomar las riendas del destino, convencida de que de ella depende la suerte de sus seres queridos y de su patria. Todo ello al alto precio de la humillación que las fuentes realzan con notas de grave conmoción y patetismo: «Señor, postrada a vuestros pies imploro / vuestra piedad con lágrimas amargas. / Humillada a los pies del homicida / de su esposo [...]» (I, vi ${ }^{29}$.

\section{Acto segundo}

El segundo acto empieza con el encuentro de Hécuba y Ulises, prosecución del anterior con Pirro, que muestra el protagonismo de «la madre» en la negociación en acto, iconográficamente reforzada con la imagen clásica de Hécuba «a los pies de». La figura de Ulises aparece en Hécuba de Eurípides, y, flanqueado por Calcas, en las Troyanas de Séneca y en Polixena de Legouvé. Como en la pieza euripidiana, Ulises, fiel a los prejuicios y respetos humanos de la tradición, es el portador de la voluntad de los griegos y el que se encarga de imponerla a la madre suplicante; papel que en la tragedia de Racine cumple Orestes en cuanto emisario de la voluntad de su padre Agamenón.

Al pretexto de las bodas de Pirro mal vistas por el pueblo, Marchena añade arbitrariamente el requerimiento que Polixena dé la mano a otro esposo (II, i) so pena de poner en peligro la vida de Astianacte. No queda claro al público, por lo menos en esta su primera aparición, hasta qué punto Ulises obra lealmente acatando la voluntad de Agamenón e identificándose con el interés «sagrado»

\footnotetext{
29 La escena de Hécuba «a los pies de» implorando la salvación de los suyos se encuentra en Hécuba de Eurípides, en las Troyanas de Séneca («Ad genua accido / supplex, Ulixe, quamque nullius pedes / novere dextram pedibus admoveo tuis», vv. 691-693 ), en Racine (Andrómaca a los pies de Pirro, III, vi) y en Legouvé (II, ii).
} 
de su patria, como dice en dos ocasiones ${ }^{30}$ y como parecen indicar las palabras que pronuncia al abandonar el escenario (II, vi), las cuales no suenan ni a falsas ni a irónicas. En cualquier caso, como el espectador constatará más adelante, Ulises posee los rasgos que le atribuye el código mitográfico ${ }^{31}$ : su «elocuencia persuasiva» (II, i) remite al «audax orator» ovidiano (Metamórfosis, XIII, v. 196) que recurre al engaño para persuadir a la madre en favor de la causa de los Griegos (v. 193) y encuentra una justificación moral al engaño mismo: «Si simulasse vocas crimen»... (v. 299). Astuto y perspicaz, buen conocedor del ánimo humano al punto de intuir el amor oculto de Polixena («Si no me engaña mi prudencia, / una insana pasión el pecho agita / de vuestra malhadada Polixena», II, i), nuestro Ulises encarna la «prudencia» maquiavélica propia del ancien régime y la servil e interesada lealtad al Poder constituido, violento, inhumano y bárbaro, como denuncia Hécuba con la ironía que es propia de la Andrómaca raciniana: «y de bárbaras trata las naciones» (II, i).

La segunda escena contempla el primer encuentro entre madre e hija. Acaso recordando la Polixena de Legouvé («par cette tendresse / Dont toujours les doux noeuds ont lié nos deux coeurs», II, iii), nuestro dramaturgo da un giro íntimo y confidencial a un diálogo que en otras piezas es fundamentalmente suasorio. Marchena ha elegido como heroína de su tragedia la menor de las hijas de Hécuba, ausente, como personaje escénico, de casi todas las obras que tratan de ella, como indicando su ausencia decisional en el tablero de juego de la acción política. Como en las Troyanas de Séneca, en ella convergen circunstancias y rasgos que pertenecen a Ifigenia; la firmeza, la nobleza de ánimo, el sentido de la propia dignidad, no bastan para conferirle aquella determinación «viril» que hallamos en las «madres», Hécuba y Andrómaca. Marchena la muestra retirada en el hogar, protegida por su confidente y aun por su madre, pues a diferencia del tópico ${ }^{32}$, representa menos el único y último apoyo de su madre, que la hija necesitada del amparo que ella misma y la nodriza le prodigan: «Ven a mis brazos, hija mía, / ¿quién mejor que tu madre, de tu llanto / puede agotar la vena?» (II, ii).

El contraste entre madre e hija se desarrolla en este primer diálogo a través de un tema grato a las fuentes clásicas, presente también en las dos tragedias francesas aquí consideradas. La admiración y respeto que inspiran a Hécuba la

30 También el Ulises de Legouvé: «Madame, je gémis que mon devoir austère [...] Si j’osais la sauver, je trahirais la Grèce» (III, iii).

31 Eurípides: «L’astucieux au séduisant langage, le flatteur des foules» (Hécuba, vv. 131-132); Séneca: «Nunc advoca astus, anime, nunc fraudes, dolos / nunc totum Ulixem» (Troyanas, vv. 613-614).

32 También en nuestra tragedia: «Ven, descansa en mi seno, único apoyo / de mi cansada edad; sola reliquia / de tantos hijos míos [...] Por ti sola de madre el dulce nombre / escuchan mis oídos con delicia» II, ii). 
integridad moral y nobleza de ánimo de Polixena no le impiden considerar la inutilidad e inoportunidad de resistir a una fuerza desproporcionada a las propias fuerzas, y abogar por la negociación y el compromiso. A la intransigente «virtud» que, en palabras de Racine, «pourrait vous rendre criminelle», Hécuba opone la aceptación realista de los hechos y la propia claudicación en favor de un bien personal y colectivo. En los versos «¡Oh de tantos monarcas hija digna! / Los hados no permiten que tan noble / indignación escuches; hoy cautiva / eres de Pirro; él solo tus cadenas / puede romper» (II, ii), que unen a la admiración la solución práctica del conflicto, perviven ecos de los modelos grecolatinos y aun de Racine y Legouvé ${ }^{33}$.

También el solo de la escena IV reevoca el famoso «lamento de Hécuba» de las fuentes, obsesivamente dominante en las Troyanas de Eurípides: el recuerdo de las pasadas glorias, los crímines perpetrados contra su patria y su familia por los Griegos, el infinito dolor causado por la muerte de sus seres queridos, al que ahora se añade el sacrificio inminente de los últimos descendientes de su estirpe, Polixena y Astianacte (Marchena no menciona a Polidoro), consuelo y apoyo de su vejez cansada.

El nuevo encuentro de Pirro y Hécuba (escena V) muestra hasta qué punto nuestro dramaturgo sigue teniendo delante el texto de Racine. El diálogo se abre con Pirro corriendo al encuentro de Hécuba («¿Qué me ordenáis, señora? ¿De mi dicha / me dais el fausto anuncio?»), como el Pyrrhus raciniano ansioso de conocer la respuesta de Andrómaca: «Me cherchiez-vous, madame? / Un espoir si charmant me serait-il permis?» (III, iv). Siguen su indignación al oír las pretensiones de Agamenón, y su furiosa rebeldía al recordar la «bárbara impiedad» del mismo. La violenta reacción de Pirro, herido en su amor propio, en defensa de su dignidad ( ¿Soy yo acaso / siervo de Agamenón? ¿Yo, de la altiva / Epiro rey, del fuerte Aquiles hijo, / adoraré sus leyes con rendida sumisión?») sigue fielmente la de Andromaque: «Oreste.- Ainsi la Grèce en vous trouve un enfant rebelle? / Pyrrhus.- Et je n'ai donc vaincu que pour dépendre d'elle?»; y luego: «Je puis l'aimer [a Hermione], sans être esclave de son père» (I, iii). Momento crucial de ambas piezas, en que Pirro toma las distancias de un poder que en sus palabras y en las de Hécuba aparece pérfido, injusto, bárbaro e impío. No

33 Así en Eurípides : «La force saura t'atteindre. Tu n'est rien; à quoi bon tant d'effort?» (Andromaca, vv. 133-134); «Sais-tu donc la conduite à tenir? Ne te fais pas de force arracher à ta fille, et n'en viens pas aux mains avec moi; mais connais ton pouvoir et tes maux présents. Il est sage, même dans le malheur, d'avoir les sentiments qu'il faut» (Hécuba, vv. 225-228); «Laisse Hector à son destin. Tes larmes ne peuvent la sauver. Honore ton nouveau maître...» (Troyanas, vv. 697-705); en Racine, Andrómaca muy a pesar suyo cede a las pretensiones de Pirro: «Ô cendres d'un époux! ô Troyens! ô mon père! / Ô mon fils, que tes jours coûtent cher à ta mère!» (III, viii); Legouvé: «N'est-il pas maître, hélas! De tes jours et des miens? / La fierté convient mal dans nos honteux liens» (II, iii), 
es casual que justo cuando el monarca se está explícitamente oponiendo a la injusticia e inhumanidad de la Ley, se mencione el sacrificio de Ifigenia ${ }^{34}$, que en el De rerum natura de Lucrecio (vv. 80 y ss.) desata la invectiva contra la religio de que se sirve el Poder iniquo para la consecución de sus fines.

Marchena sigue aún a Racine cuando menciona, entre las injusticias perpetradas por Grecia, el rapto de Briseida (« ¡A mi padre arrancó ya su injusticia / la cautiva Briseida», II, v), aludido apenas en Andromaque: «ce n’est pas la première injustice / Dont la Grèce d'Aquille a payé le service» (I, iii). El rechazo de Andrómaca en Racine, la idea de un posible rival en Marchena, en cualquier caso la fuerza y violencia del amor transforman de improviso en ira vengativa la voluntad de Pirro de ponerse al servicio de Troya aun a riesgo de su reputación y de su vida: «Songez-y bien: il faut désormais que mon coeur, / S’il n’aime avec transport, haïsse avec fureur. / Je n'épargnerai rien dans ma juste colère» (I, iv).

La respuesta airada de Pirro permite a Marchena elaborar el tema de la «prudencia» en la evolución histórica de su significado. Sinónimo de la racionalidad comportamental barroca en Ulises, deviene, en los confidentes y en Pirro «lúcido», sinónimo de la racionalidad dieciochista, atenta a la observación de los fenómenos y al conocimiento empírico de la realidad, fomentados por quien fundara El Observador. Ante la «lógica y necesaria» reacción de Pirro, Hécuba lamenta su propia «imprudencia» por no haber percibido la astuta perfidia de Ulises y por no haber previsto la reacción de su antagonista. A su vez, Pirro enamorado, enajenado, fuera de sí, o sea, fuera de su innata lucidez y clarividencia, atribuye a un fantasmagórico más allá las causas que se hallan en la realidad, incluido sí mismo como objeto de conocimiento. Bajo la «ceguera» del amor se dibuja el tema grato a Séneca, y por supuesto a los ilustrados, del sueño de la razón que engendra monstruos: «ilusión vana», «falsos miedos», argumenta Elpenor, que inducen a concebir las falsas ideas de la inmortalidad del alma y de la pervivencia de la voluntad de los muertos entre los vivos ${ }^{35}$. Como Lucrecio (como el propio Marchena ${ }^{36}$ ), convencido de que sólo con «ratione sagaci» es posible oponerse a «religionibus atque minis obsistere vatum» (v. 110), así los «sabios consejos» de Elpenor instan a oponer a los fantasmas de la mente la

\footnotetext{
34 «¿Cuando, padre sin entrañas, / a Ifigenia inmoló su mano impía [...]» (II, v).

35 En Séneca el Coro reniega de las profecías y apariciones, considerándolas «fabula», «rumores vacui verbaque inania / et par sollicito fabula somnio» (Troyanas, vv. 371 y 405-406).

36 Cfr. Marchena: «Son las terceras [verdades] aquellas cuya falsedad es demostrable [...] suponiendo siempre que ha podido y querido comunicarse la Divinidad á los mortales por otro conducto que el de la razón humana» (Lecciones..., cit. pág. 147); poco antes escribe a propósito de Lucrecio: «tan sublime cuando las vanas fantasías de la superstición ó los pánicos terrores de la muerte fulmina» (p. 135).
} 
constatación empírica de los hechos: ver y escuchar: «¿No escuchasteis, señor, [...] más bien de Polixena misma / sabréis lo cierto; vedla [...]» (II,vi).

Por último, un detalle aún relativo a las fuentes: la exclamación de Hécuba al final de la escena V, donde Pirro es comparado a un tigre, parece un calco de Legouvé : «Sous les yeux d'une mère oses-tu l'immoler, / Tigre?»(V, i).

\section{Acto tercero}

Pese a que el segundo acto finaliza con una invocación a Venus, paralela a la de Hécuba al final de la escena segunda, como oponiendo a la religión de Estado una moralidad natural de origen lucreciano ( $« \mathrm{~A}$ tus sabios consejos obedezco. Madre del crudo amor, Venus impía [...]», II, vi), el tercer acto da comienzo con el diálogo de Ulises y Calcas, que, inseparables, encarnan la alianza del altar y el trono. Ambos, con respecto a Racine, equivalen a Orestes en cuanto sujeto a la voluntad de Agamenón, que a su vez, como el Agamenón de Séneca, escucha y acata los vaticinios mendaces de Calcas.

En las palabras iniciales de Ulises se perciben las del Orestes raciniano y las del Ulises de Legouvé. El primero habla de «pitié funeste» y del temor de los griegos mientras siga en vida el hijo de Héctor; el segundo, dirigiéndose igualmente a Pirro, exclama en términos similares: «n'écoutez plus une pitié funeste, / Et d'un sang nécessaire accordez-nous le reste» (IV, ii). Así Marchena: «El fuego de los griegos en pavesas / redujo la enemiga Troya en vano, / mientras respiere, Calcas, el linaje / de Héctor. Sacrifiquemos al sagrado / interés general otros respetos» (III, i).

En conversación con su cómplice y confidente, Ulises revela ahora su verdadera naturaleza maquiavélica de animal al acecho del momento favorable que depara la Fortuna: «La fortuna nos sirve. Polixena / no cura sus furores ni sus llantos [...] Tan preciosos momentos no perdamos»(III, i). Legouvé, poniendo junto a Ulises un Calcas cínico y sanguinario, enfatiza el chantaje de la religión como instrumentum regni, mientras que, de momento, Marchena subraya el espíritu de observación del vate y su penetración en el estudio de la circunstancia en que debe actuar para conseguir sus fines: «Hécuba [...] repugna a este himeneo; Pirro irritado / a su rabia sin freno se abandona [...] ¿No conoces / de su ciego furor arrebatado / el ímpetu fogoso?» (III, i). Ambos, en efecto, observan y «escuchan» a escondidas cuanto acaece ante sus ojos, que es el espectáculo formado por la escena siguiente.

El inicio de esta segunda escena nos conduce directamente a las Troyanas de Séneca. No veo razón alguna para considerar el sueño de Polixena un 
préstamo al de Athalie de la tragedia homónima de Racine (II, v), como sugiere en cambio Menéndez Pelayo. Marchena no hace sino injertar el sueño premonitor de Andrómaca anunciándole la muerte de su hijo Astianacte (Racine) y el sueño de Hécuba en el que prevé la muerte de Polixena (Eurípides, Hécuba, vv. 90-91), en el sueño que Polixena «cuenta» ahora a su aya, vaticinador de su propia muerte. Nada más lógico, habida cuenta que en nuestra tragedia las dos figuras femeninas se hallan perfectamente fundidas. El paralelismo entre ambos textos es evidente no sólo porque en el sueño nocturno contado por la Andrómaca senecana ésta ha oído las voces de su marido Héctor y ha tratado en vano de abrazar su imagen desvaneciéndose en sus brazos, sino incluso por el préstamo, prácticamente una cita, de la hermosa imagen de la noche y el carro estrellado a raíz del apacible sueño de los mortales en contraste con el insomnio que atormenta a los desdichados: «La noche en la mitad de su carrera / guía silenciosa su estrellado carro», etc. (III, ii); y Séneca: «Partes fere nox alma transierat duas / clarumque septem verterant stellae iugum», etc. (vv. 438 y ss.). Como Andrómaca, también Polixena ve en sueños a su adorado Aquiles e intenta abrazarle, preguntándose dónde ocultarse a sí misma, como hiciera aquélla al preguntarse azorada dónde esconder a su hijo. Versos hay casi idénticos: «¿Dónde me ocultaré? ¿Quién de su airado / enojo me liberta? Héctor valiente, / perdona a Polixena tus agravios, / y defiende su vida»; y en Séneca: «Heu me, quis locus fidus meo / erit timori quaeve te sede occulam?» (vv. 476477), y luego: «qui semper, etiam nunc tuos, / Hector, tuere: coniugis furtum piae / serva» (vv. 500-502).

Las interrupciones del aya al relato de Polixena representan una repetición del anterior diálogo entre Pirro y Elpenor, en el que de nuevo entra en juego la antítesis racionalidad / irracionalidad anteriormente mencionada. Como antes el confidente de Pirro, Merpandra invita ahora a Polixena a dejarse de presagios y sueños y a atender a la realidad y a las verdaderas causas (el furor de Pirro) con el instrumento de la Razón-Prudencia: «Polixena, / ved que agitada de terrores vanos, / olvidáis que de Pirro los furores / vuestra vida amenazan. [...] ¿Por qué le confesasteis, imprudente, / vuestro amor?» (III, ii).

La intervención de Pirro nos conduce otra vez al texto raciniano. Sordo a los consejos de Elpenor, Pirro decide inmolar a Polixena escudándose en la presunta reclamación de la sombra de Aquiles y en la no menos presunta responsabilidad de Polixena en la muerte de su padre, que los hechos ahora parecen confirmarle. La decisión provocada por el rechazo de la amada y la engañosa «justificación» son muy parecidas a las de Pyrrhus, quien con ello tranquiliza momentáneamente su mala conciencia : «J'ai songé, comme vous, qu'à la Grèce, à mon père, / A moi-même, en un mot, je devenais contraire» (II, iv). 
Interesante la escena IV, donde se enfrentan Pirro y Ulises-Calcas. El anticlericalismo de Legouvé antes eludido, surge ahora con violencia al denunciar Pirro la impostura del sacerdote que dice comunicar con los muertos y conocer su voluntad. El tema que Séneca afronta en forma hipotética ${ }^{37}$ se entrelaza con el de la impostura de la religio, que en Lucrecio se desata a raíz, justamente, del inhumano sacrificio de Ifigenia: «saepius illa / religio peperit scelerosa atque impia facta. / Aulide quo pacto Triviai virginis aram / Iphianassai turparunt sanguine foede» (vv. 82-85). A la locura de una religio que exige sangre inocente en aras del resentimiento y de la venganza, la razón y la voluntad libre de Pirro opone la pietas en aras de la reconciliación y la justicia: «Jamás en este sacrificio impío / Pirro consentirá». Con ello se acerca de nuevo al Pirro raciniano y al de Legouvé $^{38}$, sujetos como él mismo a los innumerables vaivenes de su ánimo.

La escena VII opone a la mentalidad fideísta de Hécuba la libertad mental que, pese a todo, caracteriza a Pirro, que es la que le permite poner en entredicho las viejas creencias en la presunta justicia y piedad divinas y aun en la existencia de un dios cualquiera ${ }^{39}$, que Hécuba mantiene firmemente asumidas: «Dioses sacros, / que el perjurio vengáis y la crueza» (III, vii). Así pues, antes de entrar en el momento culminante de la acción, esto es, la inmolación de Polixena, Marchena deja sentada una visión del mundo a merced de la «casualidad ciega» y la idea de un destino en manos ya no de la voluntad divina sino de la libertad humana.

Para «representar narrando» el sacrificio de Polixena, nuestro autor se aparta de sus predecesores franceses y retorna a las fuentes del clasicismo grecorromano. El relato da comienzo, a modo de anacrusa, en la penúltima escena del tercer acto con el lamento de Hécuba al verse arrancar de sus brazos a la sola hija que le queda de su numerosa prole: «Hija, de mi vejez único apoyo, / ¿quién te arrancó de mis amantes brazos? / ¡Ay! ¡Tórname mi hija!» (III, vii). Versos en los que resuena el famoso «rapta sinu matris» de Ovidio (Metamórfosis, XIII, vv. 449-450), basado, a su vez, en Hécuba euripidiana: «tu me verras, misérable, misérablement arrachée à ton bras»; «N'arrache pas mon enfant de mes bras» (vv. 202-204 y 280, respectivamente).

Como en Eurípides y Séneca, el espectador «ve» el sacrificio a través de la relatio de un nuntius (en las Troyanas de Eurípides es la propia Andrómaca,

\footnotetext{
37 «Verum est an timidos fabula decipit / umbras corporibus viveres conditis [...]?» (vv. 371-372); la respuesta de Séneca es el epicureo «post mortem nihil est» (v. 397). (V, ii).
38 «ses vertus [...] ont arraché, madame, à ce bras égaré, / L’homicide couteau qu'ils appellent sacré»
39 También en Legouvé Pirro es el racionalista ilustrado frente al vulgo «amoureux de prodiges» (I, iii).
} 
en Hécuba, Taltibio), que queda así equiparado a la voz narrante de Ovidio. El nuncio es aquí el amigo y confidente de Pirro, quien «reproduce» en estilo directo las palabras pronunciadas por Polixena que Séneca omite del relato. Como el Nuntius de Séneca, Elpenor anuncia con sus lágrimas («gemam», v. 1058) la mala nueva: «Mis suspiros, señor, mi lloro amargo, / ya os han dicho cuál fue su triste suerte» (III, viii), parecidamente al Taltibio euripideo: «au récit de ses malheurs, mon oeil se mouillera maintenant, comme auprès de la tombe au moment de sa mort» (vv. 519-520).

Al igual que en Séneca, Polixena llega al sacrificio en arreos de esposa («thalami more», v. 1132), como quedara ya explicitado al inicio de la escena II del segundo acto y como para el espectador quedaría claro a través del vestuario de la víctima. Marchena refuerza así el paralelismo, y la continuidad histórica, con las anteriores bodas de Polixena/Ifigenia y Aquiles. Euripidea, y ovidiana, es la escena toda del sacrificio que el poeta latino describe con emocionantes versos (Metamórfosis, vv. 475-476): el fortis animus de la víctima, la conmovida participación de los presentes, el temblor de la mano del verdugo (Calcas, como en Hécuba de Eurípides y en Ovidio), la compasión y emoción mostradas por los mismos griegos.

Más próxima a la figura silente de Séneca que a la heroína «viril» de Eurípides (Hécuba) y de Ovidio («et plus quam femina virgo», Metamórfosis, v. 451), Marchena enfatiza la conmoción que inspira su tierna edad, el esplendor de su belleza juvenil y su temblor al dirigirse al ara del sacrificio. A diferencia de los modelos, la Polixena de Marchena se dice contenta de aplacar la sombra irritada de Aquiles, de unirse con él en matrimonio y, revelando el secreto de su pasión, una novedad absoluta que se remonta a la Vida de Apolonio de Filóstrato, declara sentirse culpable por haber antepuesto el amor a sus deberes patrióticos y filiales. Ni una palabra en exaltación de la propia libertad, o del desprecio de la muerte y alabanza de la misma como paz y liberación, o del dolor que su muerte acarrea a su madre ${ }^{40}$, o de lo absurdo del sacrificio, como en Ovidio ( $«$ Haud per tale sacrum numen placabitis ullum», v. 461), o de su pudor, unánimemente resaltados en las fuentes.

Terminado el parlamento de la víctima, el narrador no se demora ni en la intrepidez de su gesto ni en su recato, que tanto Séneca como Ovidio enfatizan en su caída («super terram defecto poplite labens», Metamórfosis, v. 477), ni en el espectáculo de la sangre que, en Séneca, absorbe el sepulcro voraz de Aquiles: «totum sanguinem tumulus bibit» (v. 1164). Todo queda reducido a un simple, casi dulce «ya su sangre bañaba los altares», que subraya la contigüidad del rito

\footnotetext{
40 Como en la tragedia de Legouvé: «Ma mère, je meurs libre, et je meurs dans vos bras» (V, vi).
} 
fúnebre y el rito de las nupcias ${ }^{41}$ e indica que con la muerte de Polixena se lleva por fin a término, en una dimensión simbólica y eterna, el suspirado desposorio, es decir, la suspirada reconciliación: «con él unida, en los Elíseos campos / eternamente viviré contenta», recuerdo del senecano, «Polixene miseranda, quam tradi sibi / cineremque Achilles ante mactari suum, / campo maritus ut sit Elysio, iubet» (vv. 942-944).

Relevante, a mi juicio, que Marchena, a diferencia de Eurípides y parecidamente a Séneca, introduzca entre el público que asiste a la ceremonia a griegos y troyanos en un dolor compartido que brota del común y humano sentimiento de la pietas: «omnium mentes tremunt, mirantur ac miserantur» (Séneca, Troyanas, vv. 1147-1148). A título de curiosidad no desprovista de interés, señalo que la escena del sacrificio nupcial de Polixena y Aquiles a la presencia de griegos y troyanos se halla reproducida en un sarcófago ático conservado en el Museo del Prado de Madrid ${ }^{42}$.

Clamorosa es la sustitución del episodio final propuesto por los modelos clásicos con un final en el que vienen a converger la reacción de Hécuba tras la muerte de Polidoro narrada en las fuentes clásicas, y los furores de Orestes con que concluye la Andromaque de Racine. Ya no el recuerdo de las Troyanas que recogen piadosas el cuerpo de la víctima, como Hécuba en Ovidio («Quae corpus complexa animae tam fortis inane», v. 488), o la sepultura que ésta, bajo el peso del dolor y de la impotencia, dispone para el cuerpo de su hija, como en Hécuba euripidea (v. 510). Terminado el relato, surgen de improviso los improperios de Hécuba furiosa de las Troyanas de Séneca («mactator senum», v. 1002) en un grito que recuerda los ladridos descritos por Ovidio (v. 404), y la explosión de indignación y venganza que sigue a la muerte de Polidoro, sea en las Troyanas de Eurípides, sea en la Metamórfosis ovidiana («facit ira nocentem», v. 562); en tanto que en la maldición proferida en su última intervención resuenan las palabras de Taltibio en las Troyanas de Eurípides («Une fureur démoniaque t'emporte, infortunée, après tant de malheurs», vv. 1284-1285) y las del coro de Hécuba referidas al malvado Polimestor: «A des actes honteux, terrible châtiment» (v. 1086).

Es más. Con la mención de las Euménides, Marchena se conecta ora con el mito de los furores de Orestes en la tragedia homónima de Eurípides, donde las Erinnias, invisibles a Menelao, existen tan sólo en su subconsciente, ora con el final conclusivo de la tragedia de Racine en la persona de Orestes, donde

\footnotetext{
41 Sobre ello véase Giuseppe Aricò, «Il silenzio di Polissena», en Studi di poesia greca e latina /Giovanni Tarditi, Milán, Vita e Pensiero, 1998, págs. 975-985.

42 Hallo la noticia en la voz POLYX ̇̀NE, Lexicon Iconographicum Mythologiae Classicae, VII, I, Zurich, Munchen, Artemis Verlag, 1994.
} 
no faltan las tradicionales sierpes que atormentan a los homicidas ${ }^{43}$ : "Pour qui sont ces serpents qui sifflent sur vos têtes?» (V, v): «¡Ceñida de culebras / una mujer!...». Cierra por fin la tragedia la atención y cuidado del confidente y amigo al «furioso» Pirro en un gesto de piadosa amistad coincidente con el final de Andromaque, mientras que la inminente salida de los griegos de regreso a su patria conduce a los versos conclusivos de Hécuba de Eurípides, las Troyanas de Séneca y Polixène de Legouvé.

$$
* \quad * \quad *
$$

Examinadas las fuentes con que nuestro dramaturgo ha reelaborado la fábula que constituye el argumento de su obra, queda por ver cómo la ha acomodado al asunto (el sujet raciniano) y la originalidad del mismo con respecto a los modelos que lo han inspirado, pues, como dice el propio Marchena, «la imitación liberal (si se me permite usar aquí esta voz) no quita que sea original un autor» ${ }^{44}$.

De entrada, Polixena se distingue de la mayoría de las tragedias neoclásicas españolas, que he tenido ocasión de analizar a fondo ${ }^{45}$, precisamente por su «asunto». En éstas prevalece el ideario revolucionario tal como lo ha ido elaborando el pensamiento ilustrado a lo largo de todo el siglo XVIII, con su crítica al absolutismo regio y las reivindicaciones de los súbditos ante el orden social y político establecido. El tema dominante es la libertad y el estado de derecho que reclama el ciudadano en cuanto representante de la patria o nación, sede de la legalidad y del único poder legítimo.

Asunto de la tragedia de Marchena es el conflicto entre las naciones y, subordinadamente, la legitimidad y aun utilidad de la guerra. Un conflicto de suma actualidad en el periodo postrevolucionario y napoleónico en que nuestro autor escribe, y que, como es sabido, dio lugar, en Francia, a un pensamiento político ora conservador, ora reaccionario, ora moderadamente revolucionario. No dudo en adscribir a este último las ideas políticas del propio Marchena ${ }^{46}$, las cuales, a mi juicio, deben ponerse en estrecha relación con la escuela francesa

43 Cfr. Virgilio, Eneida, VI, vv. 570-571.

44 Lecciones..., loc.cit., pág. 154.

45 Véase Loreto BusQueTs, «La tragedia neoclásica española y el ideario de la Revolución francesa», en Cultura hispánica y Revolución francesa, ed. Loreto BusqueTs, Roma, Bulzoni, 1990, págs. 87-127.

46 Lo dice claramente el propio Marchena: «[...] que los jacobinos y los republicanos moderados ya ocupan en la historia el lugar que á unos y á otros asignarán los venideros siglos» («Al Gobierno de Cádiz», loc. cit., pág. 195; «Políticamente, es un moderado dentro de las diversas facciones revolucionarias de la Francia de su momento» (José Osuna, «Un español olvidado: don José Marchena», Papeles de Son Armadans, 22, t. 85, núm. 253, Madrid-Palma de Mallorca, abril de 1977, pág. 22). 
de los idéologues, tanto más que colaboró en la Décade philosophique, politique et litteraire, órgano periodístico de la misma ${ }^{47}$, que dicho movimiento ejerció notable influencia en ciertos ámbitos intelectuales de nuestro país y que la obra de Destrutt de Tracy inspiró el Examen de los delitos de infidelidad a la patria, imputados a los españoles sometidos bajo la dominación francesa de Félix José Reinoso, que Menéndez Pelayo definiera el «Alcorán de los afrancesados» ${ }^{48}$.

La guerra a ultranza que los griegos mantienen contra una Troya que no representa ninguna amenaza a la propia existencia y el sacrificio humano que arbitrariamente exigen, levantan una serie de cuestiones de ética política y jurídica sobre las que Marchena se pronunció repetidamente en sus intervenciones políticas con la idea de poner fin a una guerra injustificada y de deslegitimar un gobierno inspirado en leyes injustas, bárbaras e «inhumanas». La «traición» encarnada aquí por Pirro y su padre Aquiles, plantea, a su vez, una cuestión aún más espinosa: el amor patrio conoce un límite cuando el sujeto desaprueba en su fuero interno la causa — la legalidad o la ideología — que origina el conflicto. Un conflicto que, esta vez, toca personalmente al propio Marchena, acusado en su patria de afrancesado y de «traidor», más aún por sus ideas que por su acción política. Las palabras que en su día dirigiera al Gobierno de Cádiz denotan hasta qué punto Polixena trata un asunto afín a sus preocupaciones políticas: «Nos podrán, quando mas, mirar como guerreros alistados baxo pendones enemigos; pero en la guerra todo derecho contra el vencido espira luego que éste ha rendido ó dexado las armas. A menos que quieran vmds. resucitar el antiguo derecho de guerra de los romanos, que hacian esclavos á los cautivos, ó el de los cartagineses anteriores á Gelon, que los sacrificaban a sus dioses. Acaso se inclinarán vmds. mas á esta última determinacion; y á fe que no les faltan sacrificadores, que ahí tienen todo el tribunal de la inquisición» ${ }^{49}$.

Inútil decir que la tragedia no pretende desentrañar la esencia y las contradicciones del ánimo humano, como algunos sostienen, no siendo de orden psicológico ni siquiera el propósito de Racine por más que su obra cale a fondo en el ánimo de los personajes y analice con perspicacia los movimientos del alma. Basta echar una ojeada al Sur Racine de Barthes para convencerse de ello. En este sentido, y no sólo en éste, Marchena se atiene a la simplificación

47 Sobre el movimiento de los ideólogos, puede verse el ya clásico F. Picavet, Les idéologues, París 1891, y G. Gusdorf, La conscience révolutionnaire. Les idéologues, París 1978. A dicho movimiento adhirieron numerosos intelectuales, entre los cuales se destaca Benjamin Constant, frecuentador del grupo de Coppet de Madame de Staël, con quien Marchena estuvo también relacionado.

48 Véase al respecto José Luis Abellán, Historia crítica del pensamiento español, IV, Madrid, EspasaCalpe, 1984, págs. 135 y 183 y ss.

49 «Al Gobierno de Cádiz», loc. cit., pág. 192. 
y al esquematismo dieciochista sea de los personajes, sea de la acción, sujetos a restricciones, paralelismos y simetrías que otorgan a su obra la configuración geométrica, racional y algo glacial que es propia del arte neoclásico. A ella se amoldan sus versos, que discurren con sencillez y perspicuidad con evidente tendencia a asumir la naturalidad de la prosa desbordando la frase los límites del verso con encabalgamientos que infunden al discurso un movimiento ajeno a la martilleante esticomitía y al encajonamiento versal y estrófico de los modelos franceses. Versos que, sin ser excelsos, son mucho mejores que los de la mayor parte de nuestras tragedias neoclásicas, por más que Menéndez Pelayo arremeta contra ellos por motivos no propiamente literarios.

Precisamente porque de conflicto entre naciones se trata, Marchena pone al centro de su tragedia las dos figuras emblemáticas de la guerra de Troya en su momento conclusivo: Pirro, o sea, Neoptolemo (etimológicamente, el joven combatiente), que ocupa un rol de primer plano en el exterminio de la familia real troyana, y la joven princesa Polixena, en cuya mirada, en opinión del autor de la Antología Palatina, «se refleja toda la guerra de Troya» ${ }^{50}$. Para situar a su heroína a la misma altura de Pirro, Marchena le otorga una «determinación» que toma en préstamo a la viril Andrómaca, aun evitando el carácter imperioso, sarcástico y raciocinante de la Andromaque raciniana y la agresividad de la poco agraciada Polixena de Legouvé, también contagiada de andromaquismo. Sin olvidar los males de su patria y el dolor de los suyos, la joven Polixena otorga la prioridad absoluta al amor, como Andrómaca misma, por más que en Racine divida su amor entre el esposo difunto y el hijo en peligro. Como en ella, sobre Polixena recae la responsabilidad de evitar nuevas e inútiles crueldades y sacrificios, y de levantar a su patria del presente estado de postración y esclavitud acogiendo la posibilidad que le depara Pirro, como hizo en su día Aquiles al pedir a Príamo la mano de su hija con la promesa de apoyar a Troya.

Pirro es el hombre libre que toma las distancias de su tierra de origen y es capaz de oponerse a ella cuando lo exige su sentido de la rectitud y de la justicia. Acaso por efecto del amor del que se creía inmune, Pirro, tradicional encarnación de la beligerancia cruel e inhumana, conoce la piedad y el respeto que le instan a oponerse a la legalidad inhumana y bárbara de esa Grecia que se autodefine civilizada y considera bárbaros a los pueblos que bárbaramente somete a ella ${ }^{51}$. Rebelde, llama Racine a Pirro: rebelde a las imposiciones del poder civil y eclesiástico encarnado en la pareja Ulises-Calcas, a la tradición de

\footnotetext{
50 En la voz POLYXÈNE del Lexicon Iconographicum..., cit.

51 Eurípides insiste en la presunción de Grecia de ser la representante de la ley y de la civilización: «Les lois barbares ne règlent pas notre ville» (Andrómaca, v. 243); «mais vous, les Barbares, gardez-vous de tenir vos amis pour amis»... (Hécuba, vv. 328 y ss.).
} 
los padres, a la ignorancia y superstición religiosa del vulgo, a la «legitimidad» de la venganza defendida por la violencia de los poderosos. Cuestiones que, como hemos visto, Marchena trata en términos semejantes en su mencionado escrito «Al Gobierno de Cádiz», donde, acaso pensando en Séneca, así concluye: «Vale que tan atroces órdenes nunca son obedecidas; "porque hay en la mente humana otra lei mas antigua, mas sagrada, mas poderosa que las civiles; lei dictada por la razon, y á cuya observancia compele la conciencia" ${ }^{52}$.

A diferencia de la joven Polixena y aun de la vieja Hécuba, incapaces de desprenderse de las creencias que les ha transmitido el Pasado y por esto mismo proclives a considerar al «cielo» responsable de sus actos y de sus vidas, Pirro, y los «racionales» confidentes, asumen la responsabilidad de su destino: «Je vous l'avais predit, qu'en dépit de la Grèce, / De votre sort encor vous seriez la maîtresse» (III, viii), dice Céphire a Andromaque; y Terpandra a Polixena: «las esperanzas / de la infelice Troya en vos se fundan» (I, i). Andrómaca entrará en razón, pero no así Polixena, acaso demasiado joven para abandonar esa estricta virtud que puede ser «criminelle», y demasiado enamorada para salir del recinto angosto de su corazón y de su personal desdicha. A Polixena y Pirro les une la irruencia de la juventud y la desmesura: de ahí arranca la tragedia. Pero, como a sus homónimos racinianos, les une también el amor a la vida (Venus por ellos y para ellos invocada) y la aspiración a la felicidad, de probable ascendencia lucreciana ${ }^{53}$.

Ha sido una afortunada intuición de Marchena separar los papeles de amante y madre de la Andrómaca raciniana atribuyendo el primero a Polixena y el segundo a Hécuba, emblema tradicional de la desgracia y el lamento, pero también de la mediación y la transacción. De sus labios suplicantes sale la invitación a poner fin al odio secular que atenaza a ambos pueblos. A diferencia de la «prudencia» de Ulises-Calcas, «virtud» maquiavélica abocada a los fines que exige la abominable «razón de estado», la «prudencia» de Pirro y Hécuba es la «razón política», de muy probable matriz ideológica ${ }^{54}$.

El final de Polixena deja, en efecto, enfrentadas estas dos «razones» con éxito incierto o acaso ambivalente. Aunque la escena del sacrificio vea finalmente reunidos y pacificados a griegos y troyanos en virtud del sentimiento unánime de la pietas, la maldición de Hécuba y la «locura» de Pirro dan a entender que

52 Loc. cit., pág. 194; en estas palabras se percibe la ya citada sentencia de Séneca: «Quod non vetat lex, hoc vetat fieri pudor» (Troyanas, v. 334).

53 Cfr.: «A tus sabios consejos obedezco. / Madre del crudo amor, Venus impía» (II, vi); «Lucrecio, tan perfecto cuando en el exordio de su poema invoca á la madre de los Amores» (Marchena, Lecciones..., cit., pág. 135).

54 Me refiero al mencionado movimiento francés de los ideólogos. 
triunfa al fin y una vez más la saña del odio y la venganza impuestos por una ley inhumana, bárbara, impía y arbitraria que Marchena, con Lucrecio, imputa a la potestas de los «adalides de la superstición» ${ }^{55}$ sobre las decisiones políticas: «tantum religio potuit suadere malorum ${ }^{56}$.

55 Así en «Al Gobierno de Cádiz», loc. cit., pág. 186.

56 Lucrecio, De rerum natura, v. 101. 